\title{
The Effect of Feed Rate and Cutting Speed to Surface Roughness During Hole Boring of Aluminum with Anti-Vibration Boring Bar
}

\author{
Sabi Sabev \\ Technical University - Sofia, Plovdiv Branch \\ Plovdiv, Bulgaria \\ sabi_sabev@tu-plovdiv.bg
}

\author{
Plamen Kasabov \\ Technical University - Sofia, Plovdiv Branch \\ Plovdiv, Bulgaria \\ kasabov_p@abv.bg
}

\begin{abstract}
- this study is focusing on the experimental investigation of the effects of cutting parameters on surface roughness during hole boring of 8062 aluminums with antivibration boring bar on lathe. Several experiments were conducted with different cutting conditions. Based on the results and using "Minitab 19" software, a mathematic model was made to predict the surface quality in connection with different cutting conditions. Finally, an experiment analysis was carried out to verify the analytical results.
\end{abstract}

Keywords - anti-vibration, boring bar, DOE, lathe

\section{INTRODUCTION}

In the production of details, surface quality is very important in quality determination. Good surface coating not only provides quality but also reduces production costs. Surface coating is important in terms of tolerances, reduces the assembly time and avoids the need for secondary work, thus reducing working time and leads to a general cost reduction. In addition, the high-quality surface is significant to improve the strength of fatigue, resistance to corrosion and creep life [3].

Literature is very rich in terms of turning operation owing to its importance in metal cutting. The three important process parameters in this research are speed, feed rate and depth of cut. Surface roughness of a turned work piece is dependent on these process parameters and also on tool geometry: nose radius, rake angle, side cutting edge angle and cutting edge. It also depends on the several other exogenous factors such as: work piece and tool material combination and their mechanical properties, quality and type of the machine tool used, auxiliary tooling, lubricant used and vibrations between the work piece, machine tool and cutting tool [4-7]

Throughout the world, machinists have to deal with the presence of problematic vibrations on a daily basis. Most recently, the design and development of anti-vibration tools, otherwise known as tuned or damped tools, has been applied to the boring bar.

Choosing the appropriate nose radius of the insert is also a vitally important consideration. A lower nose radius is recommended as this configuration significantly reduces the cutting forces, due to the lower contact between the insert and work piece, which helps to limit and reduce vibration. A greater nose radius creates much larger radial and tangential cutting forces that can produce increase the roughen $\mathrm{Ra}$ and unwelcome vibrations.

In order to get good surface quality, it is necessary to use optimization technique to find optimal machining parameters. This paper investigates the effect of machining parameters on the quality of surface finish. Used is design of experiment (DOE) method. Analyses the considerable influence of each experimental parameter using statistical analysis of variance (ANOVA), and after all determine the optimal parameters combination to yield the best machining condition. The machining parameters involved in this experiment are cutting speed, feed rate, and depth of cut. The main objective is to find the combination of machining parameters to achieve low surface roughness during end milling. [7] 


\section{MATERIALS AND METHODS}

For the purpose of the experiments we use ISCAR AVCD32-SVLCR-16T boring bar (Fig.1). The boring head that we use is ISCAR AVC-D32-SVLCR-16T (Fig.2), equipped with VCGT 160402-AS inserts with a $7^{\circ}$ positive flank, very positive rake angle and sharp cutting edge for machining aluminum. . The nose radius of the inserts is 0.2mm (Fig.3).

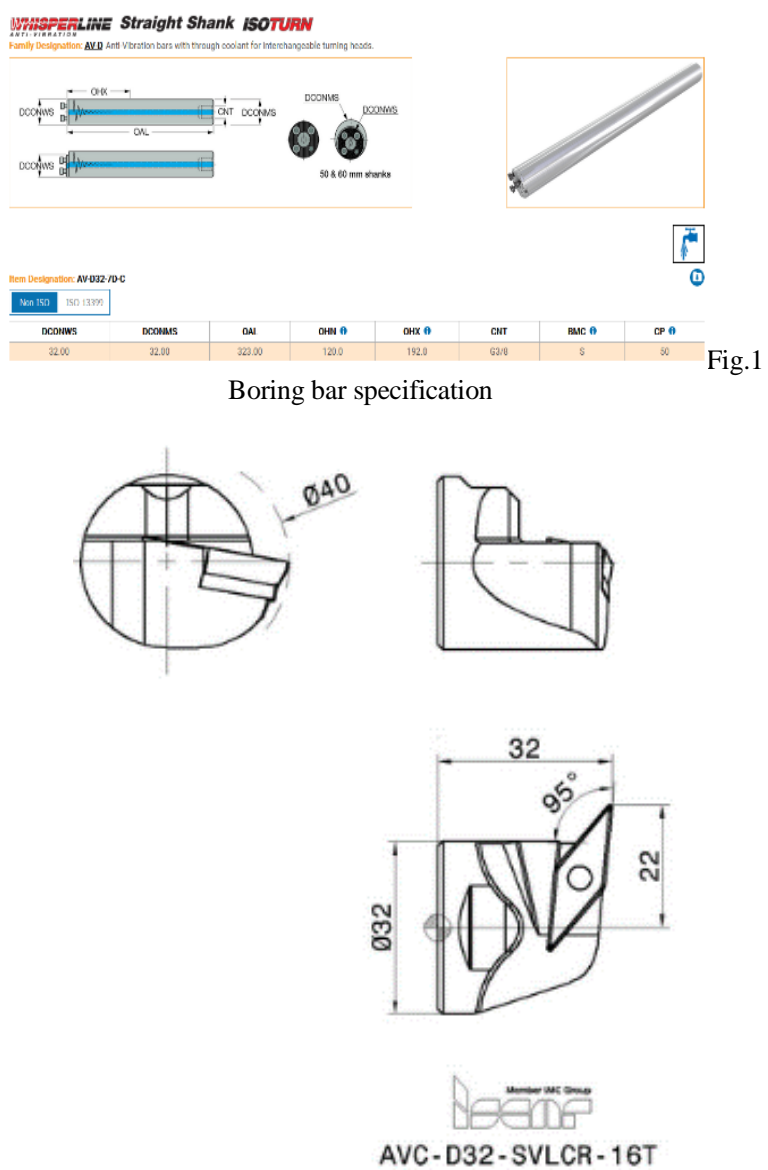

Fig.2 Boring head

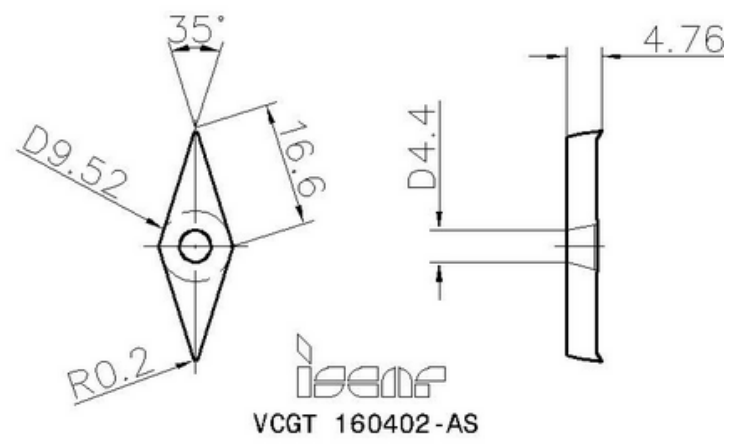

Fig. 3. Inserts VCGT 160402-AS

The machine that we use is DMG MORI CLX 400 with the following specification (Table.1):
TABLE.1 MACHINE SPECIFICATION

\begin{tabular}{|c|c|}
\hline $\begin{array}{c}\text { Max. work piece length with a tailstock } \\
\text { (can be machined) }\end{array}$ & $800 \mathrm{~mm}$ \\
\hline Max. chuck size & $315 \mathrm{~mm}$ \\
\hline Max spindle motor speed & $4,000 \mathrm{rpm}$ \\
\hline Drive power rating (100\% DC) & $17 \mathrm{~kW}$ \\
\hline Max. bar capacity diameter & $80 \mathrm{~mm}$ \\
\hline
\end{tabular}

The boring bar is held on the machine by VDI40 AVD32-JHP holder. The specification of tool holder is as follows(Fig.4):

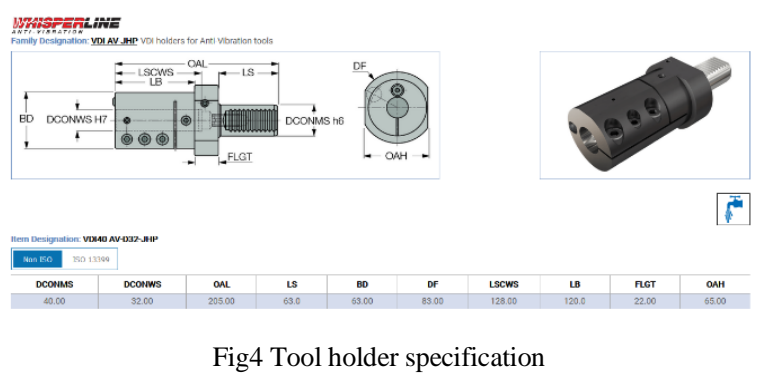

As a result of the literary survey on the experiments topic [8] the following conclusion has to be made- the cutting depth has the smallest effect on the surface finish. The value of the effect varies between $1 \%-3 \%$. The theoretical value for the surface finish proves that.

Based on the theoretical dependence (1) and (2) [1] the theoretical values for the surface finish using insert with nose radius $0.2 \mathrm{~mm}$, are calculated. The results are as follow(Table.2).

$$
\begin{gathered}
R_{t}=r-\sqrt{r^{2}-f^{2} / 4} \\
R_{a}=\frac{R t}{4}
\end{gathered}
$$

TABLE. 2 THE THEORETICAL VALUE FOR THE SURFACE FINISH

\begin{tabular}{|c|c|c|}
\hline $\begin{array}{c}\text { Feed rate } \\
\mathbf{m m} / \mathbf{r e v}\end{array}$ & $\mathbf{R t}$ & $\mathbf{R a}$ \\
\hline 0,05 & 1,569 & 0,392 \\
\hline 0,07 & 3,086 & 0,772 \\
\hline 0,08 & 4,041 & 1,010 \\
\hline 0,10 & 6,351 & 1,588 \\
\hline 0,12 & 9,212 & 2,303 \\
\hline 0,15 & 14,595 & 3,649 \\
\hline 0,16 & 16,697 & 4,174 \\
\hline 0,18 & 21,394 & 5,349 \\
\hline 0,20 & 26,795 & 6,699 \\
\hline
\end{tabular}


Environment. Technology. Resources. Rezekne, Latvia Proceedings of the $13^{\text {th }}$ International Scientific and Practical Conference. Volume 3, 314-318

A modal analysis was performed. On the basis of it were determined 5 modes for the experiments. Three trails were made for each mode to minimize the errors. That means that the total number of the experiments is 15 .

The chosen work material is AL8062-T. The dimensions of the work piece are: diameter $\Phi 80 \mathrm{~mm}$, length L-50mm and size of the boring hole $\Phi 45 \mathrm{~mm}$ Fig. 3 .

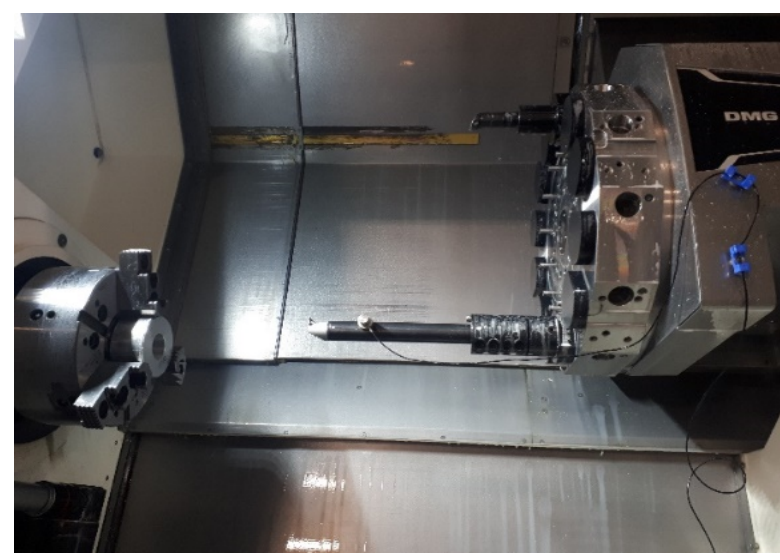

Fig. 5 Scheme of the experimental installation.

\section{RESULTS AND DISCUSSION,}

After processing the experimental samples, the roughness of the treated surfaces was measured with a roughness tester Tesa Rugosurf 20 (shown in Fig.6). This device is a compact roughness measuring instrument for mobile use. The maximum measuring range of Tesa Rugosurf 20 is $Z$ axis: $400 \mu \mathrm{m}$ and $X$ axis: $16 \mathrm{~mm}$.

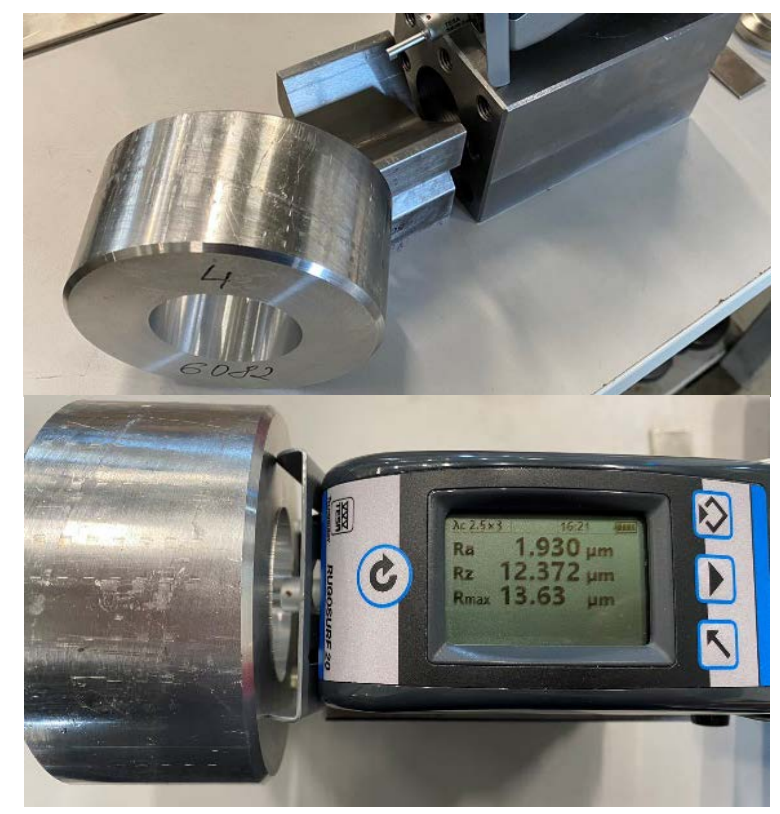

Fig.6 Scheme of the experimental installation for taking data on the roughness of the treated surface

The Table.3 shows the experiment results.
TABLE.3 ROUGHNESS MEASUREMENT DATA

\begin{tabular}{|c|c|c|c|}
\hline $\boldsymbol{N}$ & Feed & Speed & Ra \\
\hline 1 & 0,200 & 430 & 5,534 \\
\hline 2 & 0,200 & 300 & 5,151 \\
\hline 3 & 0,050 & 300 & 0,310 \\
\hline 4 & 0,050 & 430 & 0,232 \\
\hline 5 & 0,125 & 365 & 1,930 \\
\hline 6 & 0,200 & 430 & 5,371 \\
\hline 7 & 0,200 & 300 & 5,134 \\
\hline 8 & 0,050 & 300 & 0,306 \\
\hline 9 & 0,050 & 430 & 0,249 \\
\hline 10 & 0,125 & 365 & 1,824 \\
\hline 11 & 0,200 & 430 & 5,542 \\
\hline 12 & 0,200 & 300 & 5,358 \\
\hline 13 & 0,050 & 300 & 0,346 \\
\hline 14 & 0,050 & 430 & 0,230 \\
\hline 15 & 0,125 & 365 & 1,890 \\
\hline
\end{tabular}

Using the equation (3) and the value of the theoretical and experimental roughness we find the difference between them. The results are shown in tab.4

$$
\text { Error }=\frac{\text { Rat }- \text { Rae }}{\text { Rat }} \times 100 \%
$$

, where

Rat- theoretical roughness;

Rae - experimental roughness.

TAВЛЕ.4 ERROR BETWEEN THEORETICAL AND EXPERIMENTAL ROUGHNESS

\begin{tabular}{|c|c|c|c|c|}
\hline № & $\begin{array}{c}\text { Feed } \\
\mathrm{mm} / \mathrm{rev}\end{array}$ & 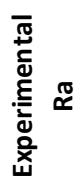 & 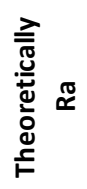 & $\begin{array}{c}\text { Error } \\
\text { [\%] }\end{array}$ \\
\hline 1 & 0,200 & 5,482 & 6,669 & 17,794 \\
\hline 3 & 0,050 & 0,321 & 0,392 & 18,197 \\
\hline 5 & 0,120 & 1,881 & 2,303 & 18,309 \\
\hline
\end{tabular}

The mathematical and statistical processing was made with the software product MINITAB 19. For the mathematical description of the target function $R a$.

The data in Table 3 is processed and the following regression model was obtained:

$R a=0,053-9,27 F+0,0007 S+172,3 F F$ 
Sabi Sabev., et al. The Effect of Feed Rate and Cutting Speed to Surface Roughness During Hole Boring

TABLE.5 COEFFICIENTS

TABLE 8. PARAMETERS

\begin{tabular}{|l|l|l|l|l|l|}
\hline TERM & COEF & SE COEF & $\begin{array}{l}\text { T- } \\
\text { VALUE }\end{array}$ & $\begin{array}{l}\text { P- } \\
\text { VALUE }\end{array}$ & VIF \\
\hline CONSTANT & 0,053 & 0,247 & 0,21 & 0,835 & \\
\hline F & $-9,27$ & 3,34 & $-2,77$ & 0,018 & 56,56 \\
\hline S & 0,000709 & 0,000513 & 1,38 & 0,194 & 1,00 \\
\hline F*F & 172,3 & 13,3 & 13,00 & 0,000 & 56,56 \\
\hline
\end{tabular}

\begin{tabular}{|c|c|c|c|c|c|c|}
\hline RESPONSE & GOAL & LOWER & TARGET & UPPER & WEIGHT & IMPORTANCE \\
\hline RA & TARGET & 0,23 & 0,8 & 5,542 & 1 & 1 \\
\hline
\end{tabular}

TABLE 9 VARIABLE RANGES

TABLE .6 MODEL SUMMARY

\begin{tabular}{|c|c|c|c|}
\hline & & & \\
\hline S & R-SQ & R-SQ(ADJ) & R-SQ(PRED) \\
\hline \hline 0,115507 & $99,82 \%$ & $99,77 \%$ & $99,67 \%$ \\
\hline \hline
\end{tabular}

\begin{tabular}{|l|l|}
\hline VARIABLE & VALUES \\
\hline F & $(0,05 ; 0,2)$ \\
\hline S & 300 \\
\hline
\end{tabular}

TABLE 10 SOLUTION

TABLE 7ANALYSIS OF VARIANCE

\begin{tabular}{|c|c|c|c|c|c|}
\hline SOURCE & DF & ADJ SS & ADJ MS & F-VALUE & P-VALUE \\
\hline REGRESSION & 3 & 79,3781 & 26,4594 & 1983,18 & 0,000 \\
\hline F & 1 & 0,1025 & 0,1025 & 7,68 & 0,018 \\
\hline S & 1 & 0,0255 & 0,0255 & 1,91 & 0,194 \\
\hline$F^{*} \mathrm{~F}$ & 1 & 2,2531 & 2,2531 & 168,88 & 0,000 \\
\hline ERROR & 11 & 0,1468 & 0,0133 & & \\
\hline LACK-OF-FIT & 1 & 0,0928 & 0,0928 & 17,17 & 0,002 \\
\hline PURE ERROR & 10 & 0,0540 & 0,0054 & & \\
\hline TOTAL & 14 & 79,5249 & & & \\
\hline
\end{tabular}

\begin{tabular}{|c|r|r|r|r|}
\hline SOLUTION & F & S & $\begin{array}{r}\text { RA } \\
\text { FIT }\end{array}$ & $\begin{array}{r}\text { COMPOSITE } \\
\text { DESIRABILITY }\end{array}$ \\
\hline 1 & 0,0887592 & 300 & 0,800000 & 1,00000 \\
\hline
\end{tabular}

TABle.11 MultiPle Response PREDiction

\begin{tabular}{|c|c|c|c|c|}
\hline VARIABLE & SETTING & & & \\
\hline F & 0,0887592 & & & \\
\hline $\mathrm{S}$ & 300 & & & \\
\hline RESPONSE & FIT & SE FIT & $95 \%$ CI & $95 \%$ PI \\
\hline RA & 0,8000 & 0,0636 & $\begin{array}{l}(0,6600 \\
0,9400)\end{array}$ & $(0,5098 ; 1,0902)$ \\
\hline
\end{tabular}

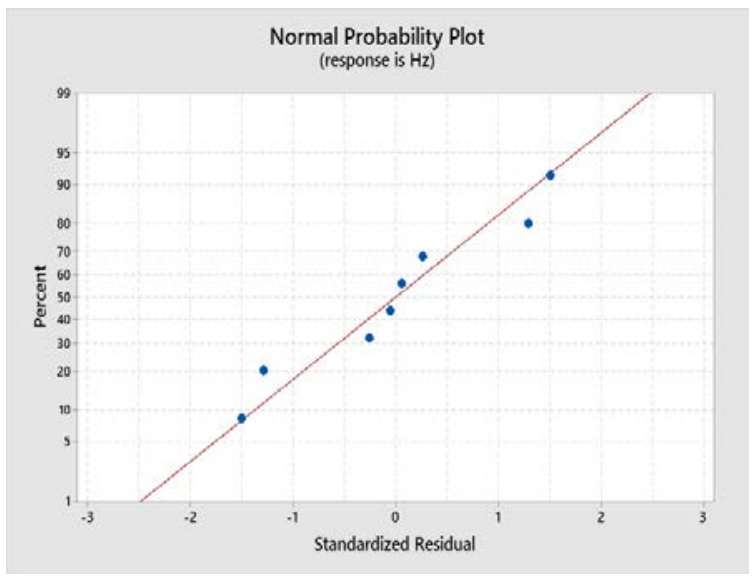

Fig.7. Standardized Residual

The analysis of the residuals was made by means of the charts of the standardized residuals, Fig.7.

The analysis of the residuals does not show disruption of the prerequisites for the regression analysis. Fig. 5 shows that all residuals are within the range \pm 2 . Therefore, a conclusion can be made that there are no gross errors.

It was performed optimization of the parameters. Criterion of optimization was $\mathrm{Ra}=0.8$. The results are presented in Tablets 8-11 and Fig.8

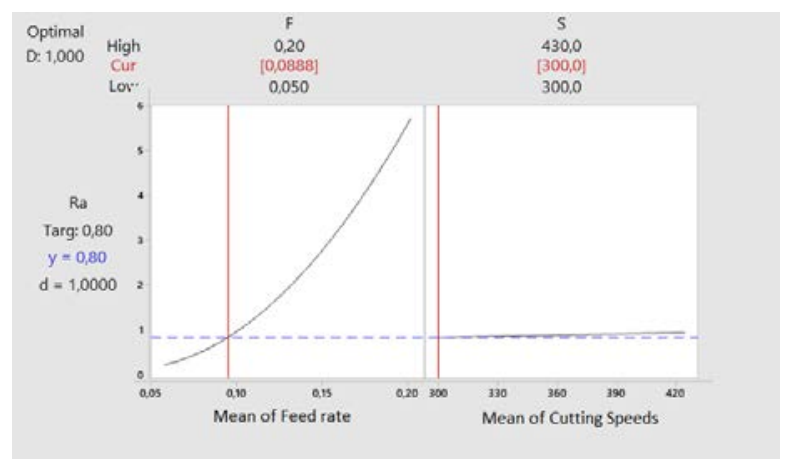

Fig.8 Predicted Value

Fig. 9 shows graphical presentation of the influence of cutting parameters on the roughness

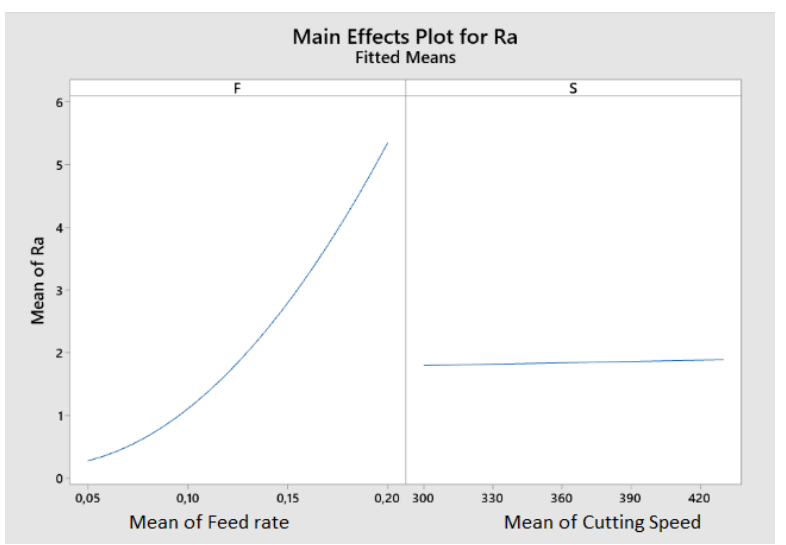

Fig.9 Factorial Plots for Ra 


\section{CONCLUSIONS}

- From the performed analysis it has been experimentally proven that the greatest influence on the roughness of the treated surface has the feeding;

- The difference between the theoretical and the experimental roughness values is approximately $18 \%$.

- A check of the predicted value of the obtained regression model was performed, which proves the reliability of the model.

- Come to the fact that the experimental roughness is lower than the theoretical one, we can say that the antivibration bar has excellent dynamic stability in the studied power range.

Acknowledgments: The authors would like to thank the Research and Development Sector at the Technical University of Sofia for the financial support

\section{REFERENCES}

[1] David J. Whitehouse, Surfaces and Their Measurement. Book 2002 https://doi.org/10.1016/B978-1-903996-01-0.X5000-2

[2] Zurita-HurtadoO. J., Di Graci-TiralongoV. C., \& Capace-AguirreM. C. (2017). Effect of surface hardness and roughness produced by turning on the torsion mechanical properties of annealed AISI 1020 steel. Revista Facultad De Ingeniería Universidad De Antioquia, (84), 55-59. https://doi.org/10.17533/udea.redin.n84a07

[3] Kumar NS, Shetty A, Shetty A, Ananth K, Shetty H (2012) Effect of spindle speed and feed rate on surface roughness of Carbon Steels in CNC turning. Procedia Engineering 38: 691-697.

https://doi.org/10.1016/j.proeng.2012.06.087

[4] J.D. ThieleandS.N. Melkote,"Effect of cutting edge geometry and work-piece hardness on surface generation in the finish hard turning of AISI 52100 steel,”Journal of MaterialsProcessing Technology, vol. 94, 1999, pp. 216-226.

[5] W.Chen, "Cutting forces and surface finish when machining mediumhardness steel using CBN tools,” International Journal of Machine Tools Manufacturing, vol. 40, 2000, pp. 455-466.

[6] S.M. Darwish,"Theimpact of the tool material and the cutting parameters on surface roughness of supermet 718 nickel superalloy,” Journal of Materials Processing Technology,Vol. 97, 2000, pp. 10-18.

[7] Samya Dahbi, Haj El Moussami, Latifa Ezzine. Optimization of turning parameters for surface rough-ness. Xème Conférence Internationale: Conception et Production Intégrées, Dec 2015, Tanger. https://hal.archives-ouvertes.fr/hal-01260818

[8] M. Nurhaniza, M. K. A. M. Ariffin, F. Mustapha, B. T. H. T. Baharudin, "Analyzing the Effect of Machining Parameters Setting to the Surface Roughness during End Milling of CFRP-Aluminium Composite Laminates", International Journal of Manufacturing Engineering, vol. 2016, Article ID 4680380, 9 pages, 2016. https://doi.org/10.1155/2016/4680380

[9] C. Rao, D. Rao, P. Srihari Influence of cutting parameters on cutting force and surface finish in turning operation Procedia Eng., 64 (2013), pp. 14051415 https://doi.org/10.1016/j.proeng.2013.09.222 